\title{
Application of Biochar for Cadmium Stabilization in Contaminated Paddy Soil
}

\author{
Marisa Oranratmanee and Warapong Tungittiplakorn* \\ Faculty of Applied Science, King Mongkut's University of Technology North Bangkok, Thailand
}

\begin{abstract}
Cadmium contamination in rice fields near zinc mines in Mae Sot District, Tak Province has been a persistent problem for decades. The contamination covers a vast area, making several soil remediation methods, such as soil washing or excavation impractical. Phytoremediation would also take several years and interfere with farming. However, there are recent reports on the potential of biochar in cadmium stabilization which resulted in reduced cadmium uptake by rice. Therefore, in this study, several biomaterials were investigated to produce the most suitable biochar for cadmium stabilization in paddy soil in Mae Sot. Rice husk, rice straw and bagasse were selected because of their availability in Mae Sot. Cadmium adsorption efficacy of biochar made from these biomaterials were analyzed using the adsorption isotherm. The results showed that cadmium adsorption by biochar from bagasse, rice husk, and rice straw were in accordance with Freundlich adsorption isotherm equation. By comparing the distribution coefficient, the adsorption efficacy of the biochar was ranked as rice straw > bagasse> rice husk. Therefore, rice straw biochar, which had the highest cadmium adsorption efficacy, was selected for stabilization experiments. After 30 days of incubating contaminated soil with rice straw biochar, the amount of extractable $\mathrm{Cd}$ using $\mathrm{CaCl}_{2}$ and EDTA were reduced significantly. The optimal application rate of rice straw biochar was $5 \%$ with the incubation period of 20 days. This warrants the next phase of this study which will be conducted in the field experiments in Mae Sot.
\end{abstract}

Keyword. Adsorption Isotherm, Cadmium, Stabilization, Biochar, Paddy, Mae Sot District

\section{Introduction}

Cadmium contamination in rice fields near zinc mines in Mae Sot District, Tak Province was reported by the International Water Management Institute (IWMI) and the Pollution Control Department (PCD). [1, 2]. According to the reports, the contamination covered a large area of paddy field downstream from the mines (approximately 6 square kilometres) as shown in Fig. 1 and 2. Cadmium concentration in paddy soil and rice grains in the contaminated area were between 0.5 to 284 $\mathrm{mg} / \mathrm{Kg}$ of soil and 0.05 to $7.7 \mathrm{mg} / \mathrm{Kg}$ of rice, respectively. These contaminations pose a health risk to human because harvested rice contained cadmium that exceeded CODEX standard of $0.2 \mathrm{mg} \mathrm{Cd} / \mathrm{Kg}$ of rice. Besides, there is also contamination in other agricultural products such as soybeans, mung beans, corn and sugarcane. [3]. Cadmium contamination could cause respiratory and circulatory disorders, including an orthopedic disorder known as ItaiItai. $[1,4]$. The contamination in soils also affected soil fertility and agricultural productivity. Hence, it is imperative to remediate the contaminated area with appropriate and effective methods.

There are several methods for remediation of heavy metals in contaminated soil. Excavation can quickly restore soil that is contaminated with a wide variety of contaminants. However, this method is limited by the cost

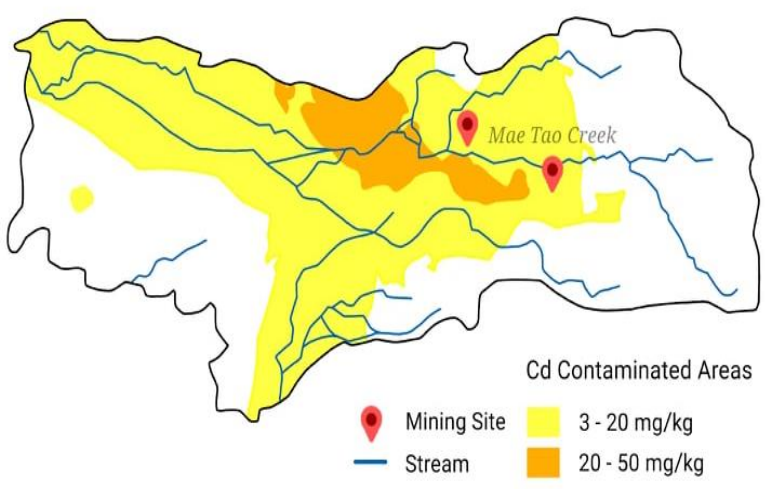

Fig. 1. Contaminated area in Mae Sot District, Tak Province [2].

of excavation, transportation, and disposal, therefore not suitable for a large contaminated area such as Mae Sot. Soil washing, which leaches contaminants from the soil with chemicals, can be done quickly but is also limited by the amount chemicals required and their effects on soil's fertility and $\mathrm{pH}$. This method can subsequently affect soil organisms and its suitability for agriculture. Biological method such as phytoremediation is relatively safe, but limited by slow plant growth and uptake [5]. Thus, this

* Corresponding author: warapong.t@ sci.kmutnb.ac.th 
method would take several years to reduce the contaminant concentration to acceptable level.

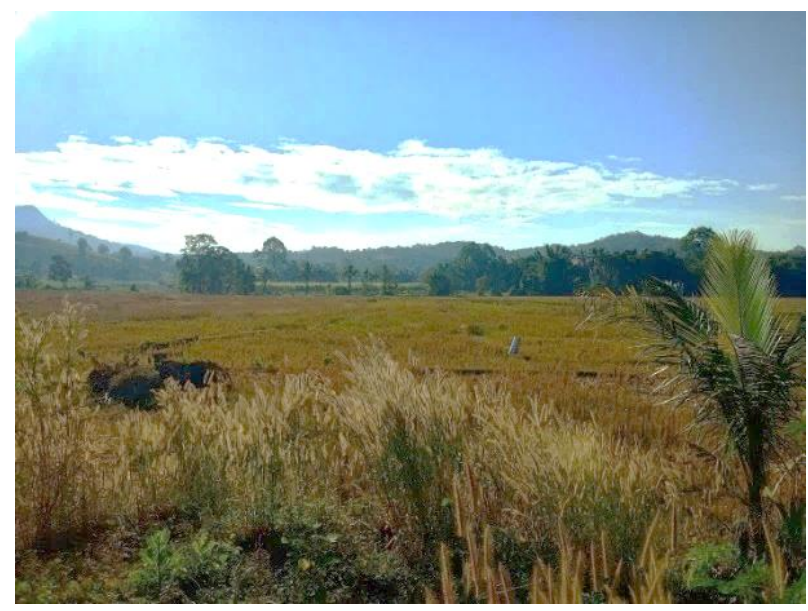

Fig. 2. Cadmium contamination in rice fields in Phra That Pha Deang Sub-district, Mae Sot District, Tak Province.

Cadmium stabilization using clay minerals or biochar have been shown in several research for their potential for treating heavy metal-contaminated soil $[4,6,7]$. Treated clay minerals were shown to adsorb heavy metals effectively from aqueous solution and immobilize heavy metals in contaminated soil $[8,9]$. Application of wheat straw derived biochar was shown to reduce the bioavailability of $\mathrm{Cd}$ and $\mathrm{Pb}$ in paddy soil and limit $\mathrm{Cd}$ uptake by rice $[7,10]$. Bamboo and rice straw biochar decreased the amount of extractable heavy metals $(\mathrm{Cd}$, $\mathrm{Cu}, \mathrm{Pb}$ and $\mathrm{Zn}$ ). [11]. Acacia biochar decreased the accumulation of $\mathrm{As}$ and $\mathrm{Mn}$ in Napier grass grown in contaminated mine tailing. [12]. Moreover, rice straw biochar was shown to reduce the accumulation of $\mathrm{Cd}, \mathrm{Zn}$, $\mathrm{Mn}$ and Ni in roots, stems and seeds of wheat. [13].

However, unlike clay minerals, biochar can be produced from various agricultural wastes by pyrolysis process. It can also be used as a soil amendment material because of its high organic carbon, the ability to retain minerals, and its water holding capacities [14]. Rice straw and bamboo biochar were found to increase the growth and yield of wheat and rice, respectively [13, 15]. Moreover, pine pellet biochar was shown to increase the growth of cucumber plug seedling in both stem and root. [16]. Therefore, biochar can be applied to contaminated soil to decrease heavy metal uptake by crops while increasing the growth and yield of the crops. This allows farmers to grow crops while remediating the soil, making this method highly suitable for solving the cadmium contamination problem in Mae Sot.

Biochar is black carbon which is very stable and can be retained in the soil for a long time. It has a large surface area with numerous functional groups which are able to adsorb heavy metals. Biochars produced from different biomass and pyrolysis temperature have different physical and chemical properties, as shown in the Table 1. The mechanisms of biochar adsorption include electrostatic attraction, ion exchange, complexation and coprecipitation at the surface of biochar as shown in Fig. 3.
Plant uptake generally requires $\mathrm{Cd}$ to be in the exchangeable form such as $\mathrm{Cd}^{2+}$, thus $\mathrm{Cd}$ could be stabilized by reducing the amount of exchangeable $\mathrm{Cd}$ by means of biochar adsorption. Additional factors include physical and chemical properties of biochar which are greatly influenced by the production temperature, the application rate of biochar in the soil, and the $\mathrm{pH}$ of the soil [17].

Table 1. Properties of different biochars.

\begin{tabular}{|c|c|c|c|c|c|}
\hline $\begin{array}{l}\text { Type of } \\
\text { Biochar }\end{array}$ & $\begin{array}{c}\text { Pyrolysis } \\
\text { Temp } \\
\left({ }^{\circ} \mathrm{C}\right)\end{array}$ & $\mathrm{pH}$ & $\begin{array}{l}\text { Surface } \\
\text { area } \\
\left(\mathrm{m}^{2} / \mathrm{g}\right)\end{array}$ & $\begin{array}{c}\mathrm{CEC} \\
(\mathrm{cmol} / \mathrm{kg})\end{array}$ & Ref \\
\hline Bagasse & 450 & 6.5 & 3.04 & 17.58 & \multirow{3}{*}{ [12] } \\
\hline Napier grass & 450 & 9.86 & 11.68 & 18.61 & \\
\hline Acacia wood & 450 & 9.13 & 25.55 & 23.83 & \\
\hline Bamboo & 750 & 9.5 & 907.4 & 15 & \multirow{2}{*}{ [11] } \\
\hline Rice straw & 500 & 10 & 36.7 & 45 & \\
\hline Rice Husk & 700 & 8.5 & 25.161 & - & \multirow[b]{2}{*}{ [18] } \\
\hline $\begin{array}{l}\text { Empty fruit } \\
\text { bunch }\end{array}$ & 700 & 9.4 & 1.89 & - & \\
\hline Populus wood & $500-550$ & 8.2 & 15 & - & \multirow{3}{*}{ [19] } \\
\hline Carozo corn & $400-500$ & 10.3 & 22.3 & - & \\
\hline $\begin{array}{l}\text { Sewage } \\
\text { sludge }\end{array}$ & $500-550$ & 8.7 & 31.4 & - & \\
\hline Scots pine & 450 & 8.56 & 9.16 & 3.41 & \multirow{4}{*}{ [20] } \\
\hline Scots pine & 700 & 8.52 & 10.4 & 2.40 & \\
\hline Silver birch & 450 & 8.69 & 5.92 & 5.09 & \\
\hline Silver birch & 700 & 9.27 & 7.17 & 5.71 & \\
\hline
\end{tabular}

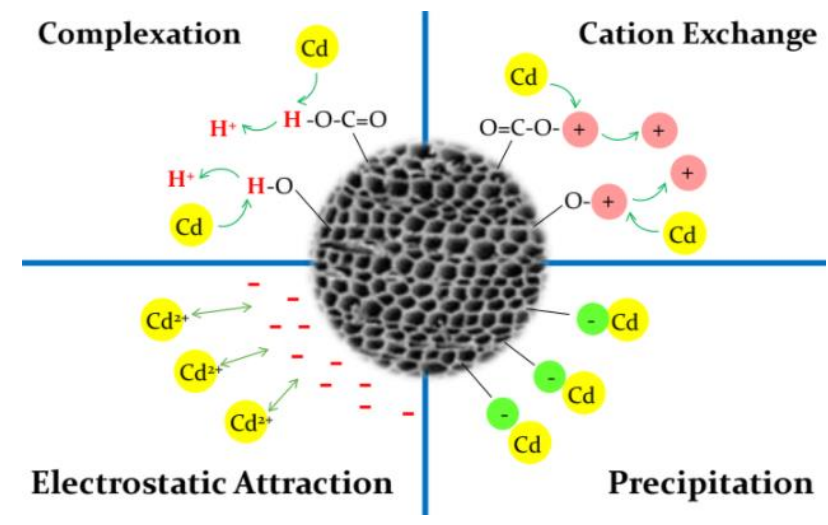

Fig. 3. Biochar - Heavy metals adsorption mechanism.

The purpose of this research is to study the efficacy of biochar made from different types of agricultural wastes in stabilizing cadmium in paddy soil. Bagasse, rice husk, and rice straw were used to produce biochar because of their availability in Mae Sot District, Tak Province. The ability of biochar to adsorb and reduce exchangeable cadmium in paddy soil was tested in lab-scale experiments. Biochar with the highest efficacy for cadmium adsorption and stabilization from this study will be applied in a field experiment in Mae Sot to provide the most effective and practical remediation method for rice farmers in the area. 


\section{Experimental Methods}

\subsection{Soil and biochar preparation}

Cadmium contaminated soil samples and rice straw were obtained from a paddy field in Mae Tao Sub-district, Mae Sot District, Tak Province as shown in Fig. 4. Bagasse biochar (BB), rice husk biochar (RHB), and rice straw biochar (RSB) were produced by pyrolysis process at $450{ }^{\circ} \mathrm{C}$ for 4 hours. The process was conducted in a 200 liter steel furnace at Huai Sai Royal Development Study Center as seen in Fig. 5. Biochar was then ground and sifted to $250 \mu \mathrm{m}$. The $\mathrm{pH}$ of paddy soil and biochar were determined according to the USEPA Method 9045D by mixing soil or biochar with water at 1:1 ratio. The $\mathrm{pH}$ of the supernatant was then measured with a Mettler Toledo F20 pH meter. The $\mathrm{pH}$ of Cd-contaminated paddy soil, uncontaminated paddy soil, BB, RHB, and RSB were determined to be $7.50,5.23,9.31,7.80$, and 10.15, respectively.

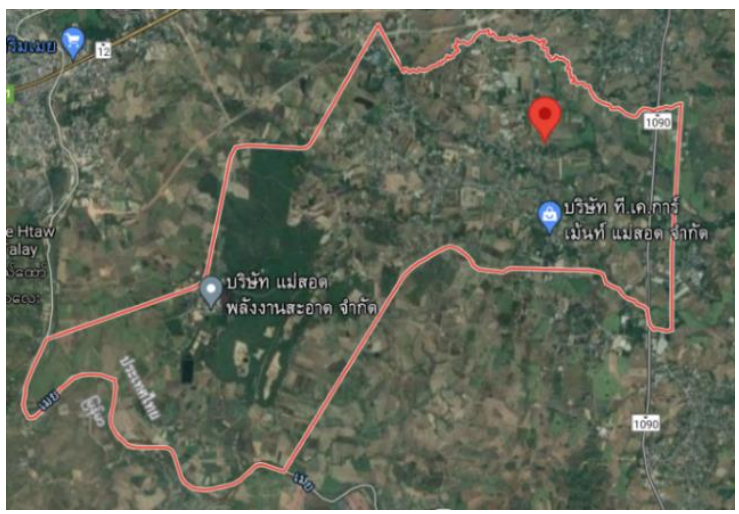

Fig. 4. The location of the sampling site in Mae Tao Sub-district, Mae Sot District, Tak Province. The red line outlines the boundary of Mae Tao Sub-district.

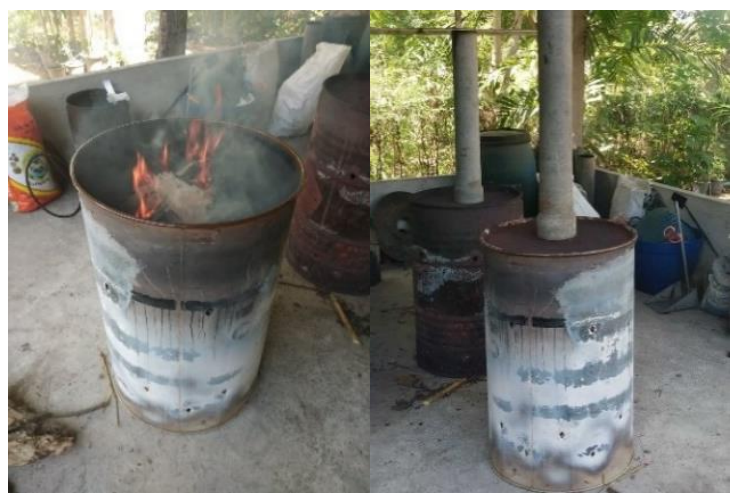

Fig. 5. Biochar steel furnace.

\subsection{Cadmium adsorption}

To study the efficacy of cadmium adsorption on biochar, $1 \mathrm{~g}$ of uncontaminated paddy soil sample was added to 20 $\mathrm{mL}$ of cadmium solution (prepared from cadmium chloride dissolved in $0.01 \mathrm{M} \mathrm{CaCl}$ ) at 5 concentrations: $10,15,20,25$ and $30 \mathrm{mg} / \mathrm{L}$. To compare the effect of biochar concentration, the concentration of biochar added to each vial was varied at $0,10,20$ and $100 \%$ of soil sample. The mixtures were shaken at $120 \mathrm{rpm}$ for a period of 24 hours. The supernatant was then filtered with No.42 Whatman filter. Cadmium concentration and $\mathrm{pH}$ of the supernatant were determined by Atomic Absorption Spectroscopy (Agilent 240FS) and $\mathrm{pH}$ meter, respectively. The amount of adsorbed cadmium was determined using Equation (1).

$$
q_{e}=\left(\frac{\left(C_{0}-C_{e}\right) \times V}{W}\right)
$$

where $q_{e}$ is the amount of $\mathrm{Cd}$ adsorbed by biochar, $C_{0}$ and $C_{e}$ are the initial and equilibrium concentration of $\mathrm{Cd}$ in the supernatant, respectively [21]. Adsorption isotherm was plotted between $q_{e}$ and $C_{e}$.

\subsection{Cadmium extraction}

To study the stabilization effect of biochar on cadmiumcontaminated soil, biochar with the highest efficacy for cadmium adsorption was incubated with $200 \mathrm{~g}$ of contaminated paddy soils for 30 days with water saturation. The amount of biochar was varied at 5 and 7 $\%(\mathrm{w} / \mathrm{w})$. Soil samples were collected at $0,10,20$ and 30 days. Cd was extracted by adding $2 \mathrm{~g}$ of soil in $15 \mathrm{~mL}$ of $0.01 \mathrm{M} \mathrm{CaCl}_{2}$ and $15 \mathrm{ml}$ of $0.05 \mathrm{M}$ EDTA and shaken at $120 \mathrm{rpm}$ for a period of 24 hours $[11,14]$. The concentration of extracted $\mathrm{Cd}$ was determined with Atomic Absorption Spectroscopy.

\section{Results and Discussion}

\subsection{Cadmium adsorption isotherm}

The cadmium adsorption isotherms of paddy soil, BB, RHB, and RSB at concentration of 10, 20 and 100\% are shown in Fig. 6-9. Least-square linear and non-linear regression were used to fit the adsorption isotherms with linear and Freundlich adsorption models, respectively. The goodness of fit of the experimental data to the adsorption models were compared using the standard error of the estimate (SE). The parameters of the adsorption models are shown in Table 2.

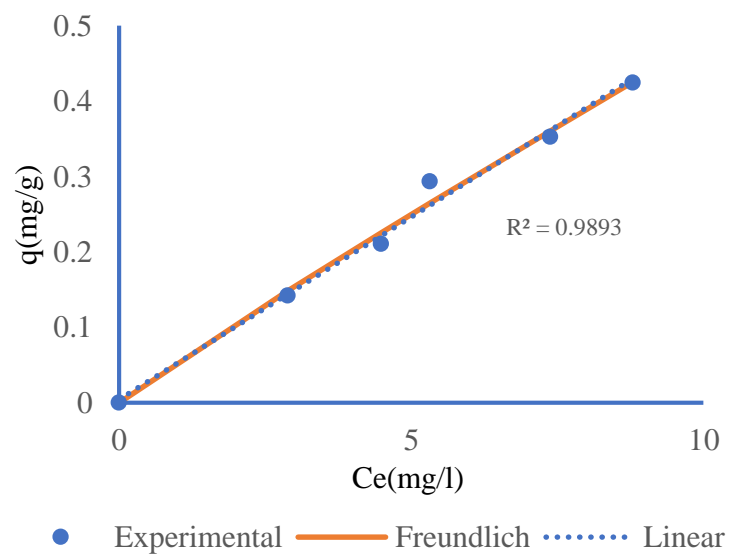

Fig. 6. Adsorption Isotherm of paddy soil. 
$10 \%$

(a)

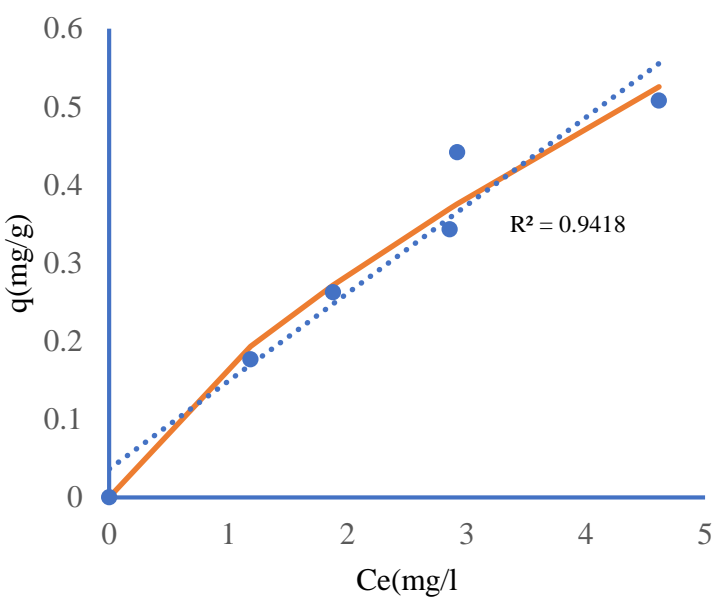

$20 \%$

(b)

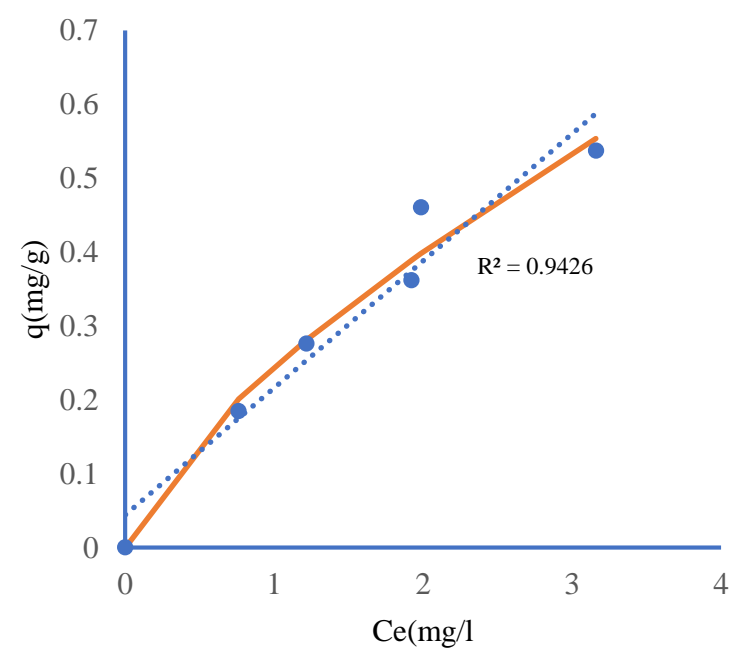

$100 \%$

(c)

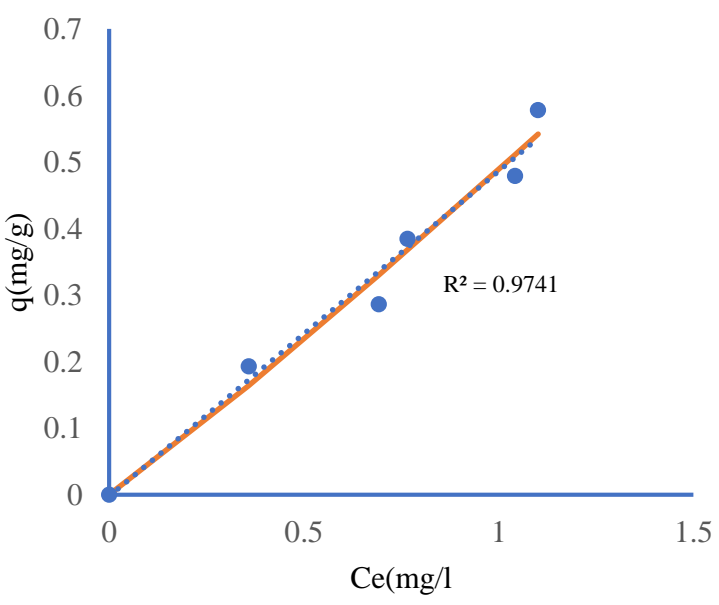

- Experimental Freundlich . Linear

Fig. 7. Adsorption Isotherm of BB with concentration of biochar at a) 10, b) 20 and c) $100 \%$
$10 \%$

(a)

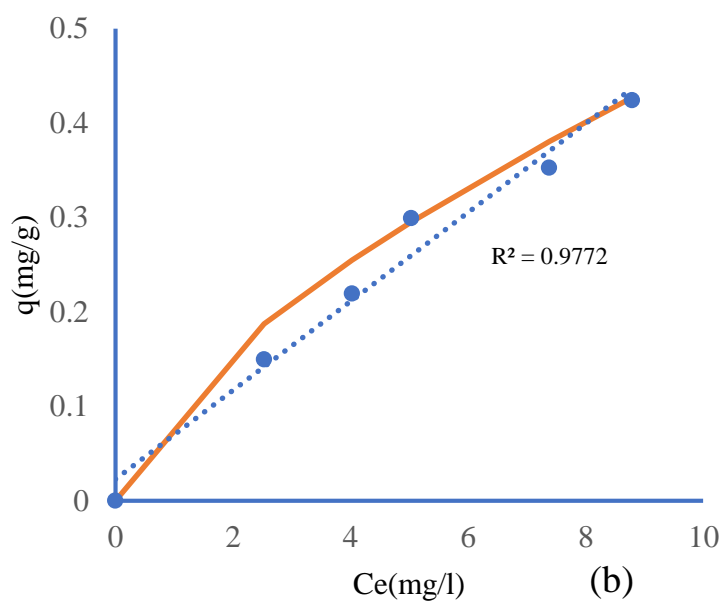

$20 \%$

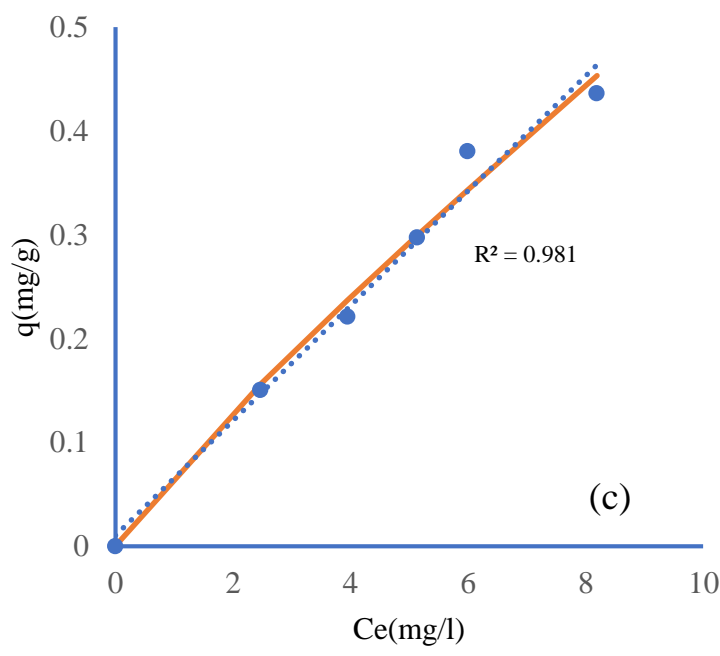

$100 \%$

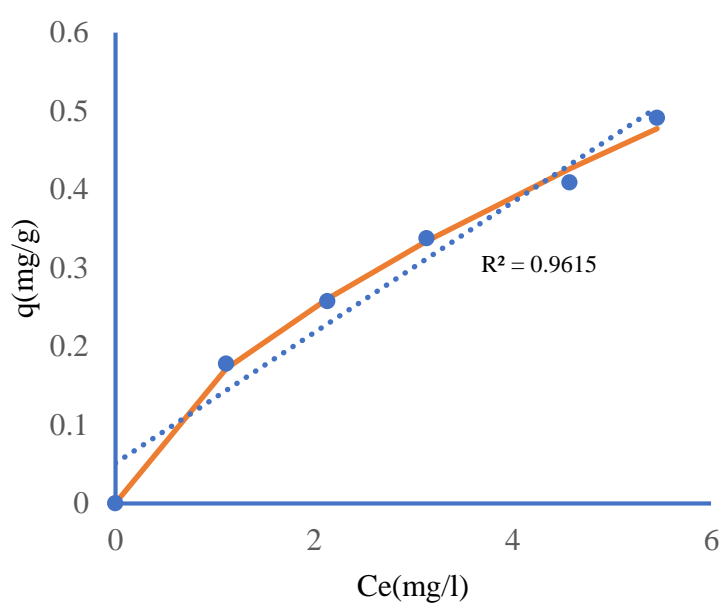

- Experimental — Freundlich ......... Linear

Fig. 8 Adsorption Isotherm of RHB with concentration of biochar at a) 10, b) 20 and c) $100 \%$ 
$10 \%$

(a)

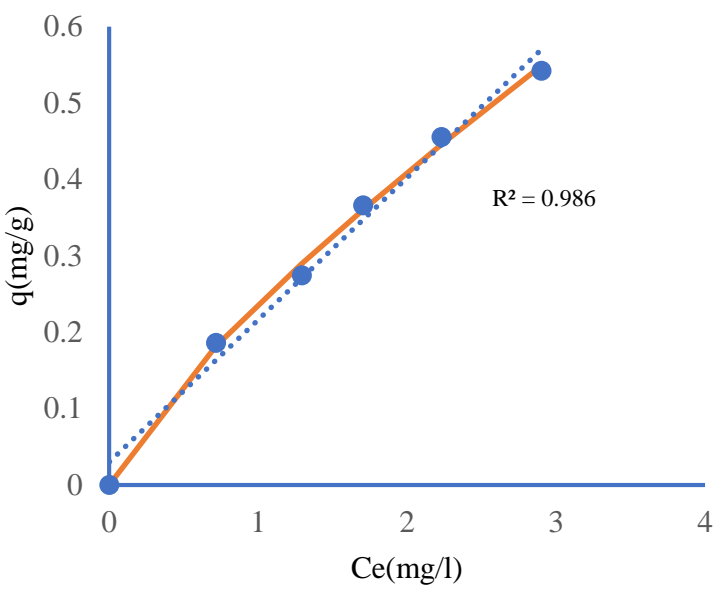

$20 \%$

(b)

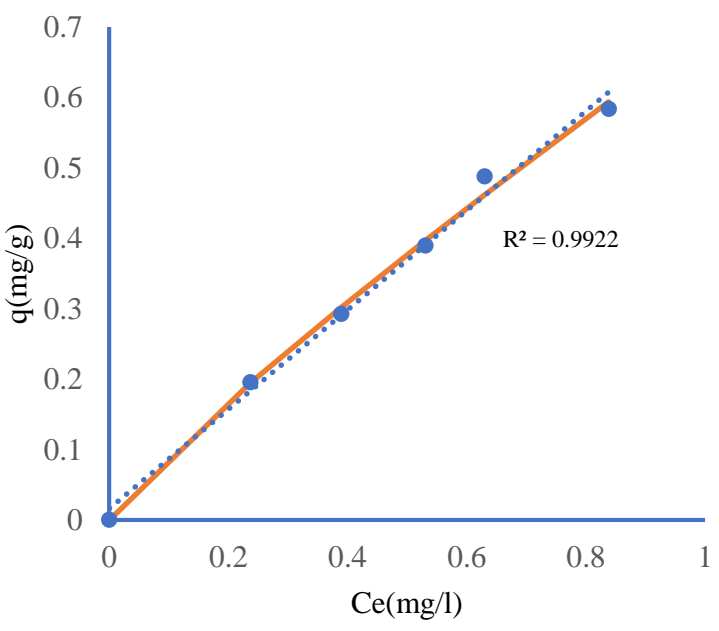

$100 \%$

(c)

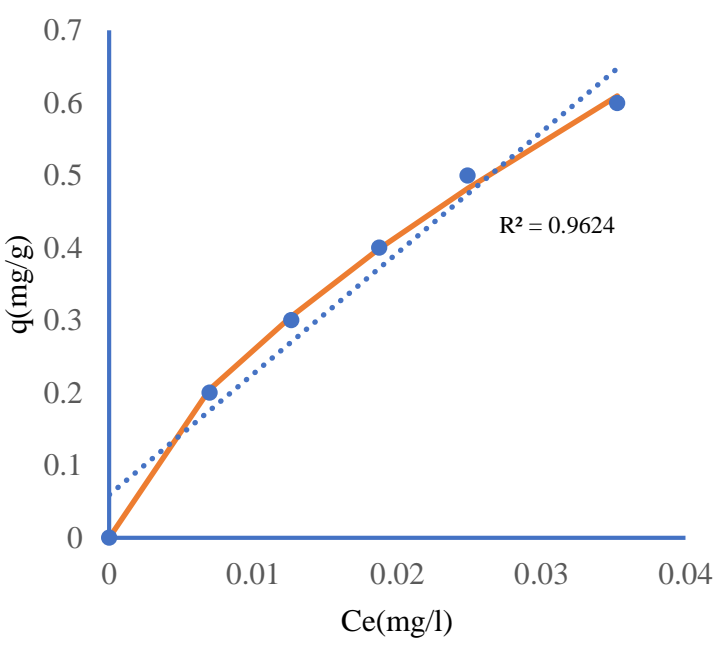

- Experimental $\longrightarrow$ Freundlich ......... Linear

Fig. 9. Adsorption Isotherm of RSB with concentration of biochar at a) 10, b) 20 and c) $100 \%$
Table 2. Adsorption isotherm parameters and standard error of estimate.

\begin{tabular}{|c|c|c|c|c|c|c|}
\hline \multirow{2}{*}{ Biochar } & \multirow{2}{*}{$\begin{array}{c}\text { conc. } \\
(\%)\end{array}$} & \multicolumn{2}{|c|}{ Linear model } & \multicolumn{3}{|c|}{ Freundlich model } \\
\cline { 3 - 7 } & & $\mathbf{K}_{\mathbf{d}}$ & $\mathbf{S E}$ & $\mathbf{K}_{\mathbf{F}}$ & $\mathbf{1 / n}$ & SE \\
\hline $\begin{array}{c}\text { Paddy } \\
\text { Soil }\end{array}$ & 100 & 0.0484 & 0.018 & 0.055 & 0.944 & 0.017 \\
\hline \multirow{4}{*}{ BB } & 10 & 0.1125 & 0.050 & 0.171 & 0.735 & 0.038 \\
\cline { 2 - 7 } & 20 & 0.1719 & 0.052 & 0.245 & 0.710 & 0.036 \\
\cline { 2 - 7 } & 100 & 0.4889 & 0.037 & 0.489 & 1.066 & 0.037 \\
\hline \multirow{3}{*}{ RHB } & 10 & 0.0471 & 0.026 & 0.101 & 0.662 & 0.021 \\
\cline { 2 - 7 } & 20 & 0.0554 & 0.025 & 0.070 & 0.889 & 0.022 \\
\cline { 2 - 7 } & 100 & 0.083 & 0.038 & 0.160 & 0.645 & 0.012 \\
\hline \multirow{4}{*}{ RSB } & 10 & 0.186 & 0.026 & 0.236 & 0.790 & 0.010 \\
\cline { 2 - 7 } & 20 & 0.7052 & 0.021 & 0.694 & 0.882 & 0.015 \\
\cline { 2 - 7 } & 100 & 16.677 & 0.047 & 5.790 & 0.673 & 0.011 \\
\hline
\end{tabular}

Table 3. The $\mathrm{pH}$ of paddy soil, BB, RHB and RSB.

\begin{tabular}{|c|c|c|}
\hline Biochar & conc. $(\boldsymbol{\%})$ & $\mathbf{p H}$ \\
\hline Paddy Soil & 100 & 5.47 \\
\hline \multirow{2}{*}{ BB } & 10 & 6.01 \\
\cline { 2 - 3 } & 20 & 6.49 \\
\cline { 2 - 3 } & 100 & 8.59 \\
\hline \multirow{2}{*}{ RHB } & 10 & 5.78 \\
\cline { 2 - 3 } & 20 & 5.91 \\
\cline { 2 - 3 } & 100 & 7.53 \\
\hline \multirow{2}{*}{ RSB } & 10 & 6.76 \\
\hline & 20 & 7.05 \\
\cline { 2 - 3 } & 100 & 9.90 \\
\hline
\end{tabular}

\subsection{Comparison of cadmium adsorption efficacy}

Cadmium adsorption efficacy of paddy soils and biochar can be determined by comparing the constants $\mathrm{K}_{\mathrm{d}}$ in linear adsorption isotherm or $\mathrm{K}_{\mathrm{F}}$ in Freundlich isotherm depending on which model has the best fit. By comparing the SE, it was found that the adsorption isotherm of paddy soil and biochar fit better with Freundlich adsorption isotherm model. The $\mathrm{K}_{\mathrm{F}}$ value showed that all types of biochar had more ability to adsorb cadmium than paddy soil. Moreover, higher concentration of biochar increased the adsorption efficacy. These results corresponded well to the results reported by Maichu et al., [14]. By comparing $\mathrm{K}_{\mathrm{F}}$, it was found that RSB has the highest affinity for cadmium and RHB has the lowest affinity for cadmium. Furthermore, the $\mathrm{K}_{\mathrm{F}}$ of RSB is almost 11 times higher than $\mathrm{BB}$ and 36 times higher than RHB. This means that RSB has the highest efficacy for cadmium adsorption. The reason that RSB has very high cadmium adsorption efficacy could be due to its high surface area and CEC as shown in Table 1. High $\mathrm{pH}$ could also contribute to the precipitation of cadmium. The $\mathrm{pH}$ of 
RSB was 9.90 as can be seen in Table 3 . When RSB was mixed with soil, it raised the $\mathrm{pH}$ of the soil from 5.47 to 7.05. With higher $\mathrm{pH}$, the CEC of the soil could have been increased as well [22]. These mechanisms have also been reported by other research. [23, 24].

\subsection{Cadmium extraction}

From the results of previous experiment, RSB, which had the highest efficacy for cadmium adsorption, was selected to be tested for cadmium stabilization efficacy. From the results shown in Fig. $\mathbf{1 0}$ and 11, it can be seen that the value of $\mathrm{CaCl}_{2}$ extracted $\mathrm{Cd}$ from cadmium contaminated soil before the treatment was $1.05 \pm 0.20 \mathrm{mg} / \mathrm{kg}$. When the soil was mixed with RSB at 5 and $7 \%$, the amount of $\mathrm{CaCl}_{2}$-extracted $\mathrm{Cd}$ was immediately reduced to $0.67 \pm$ 0.41 and $0.49 \pm 0.22 \mathrm{mg} / \mathrm{kg}$, respectively, and further reduced to $0.18 \pm 0.00$ and $0.10 \pm 0.01 \mathrm{mg} / \mathrm{kg}$ in 20 days. After that the amount of $\mathrm{CaCl}_{2}$-extracted $\mathrm{Cd}$ remained almost unchanged. Similarly, the amount of EDTAextracted Cd before the treatment was $9.23 \pm 1.38 \mathrm{mg} / \mathrm{kg}$. After the application if RSB at 5 and $7 \%$, the amount of EDTA-extracted Cd was immediately reduced to $7.47 \pm$ 1.86 and $4.72 \pm 0.19 \mathrm{mg} / \mathrm{kg}$, respectively, and further reduced to $2.35 \pm 0.20$ and $2.21 \pm 0.22 \mathrm{mg} / \mathrm{kg}$ in 10 days. After that the amount of EDTA-extracted $\mathrm{Cd}$ remained almost unchanged. These results are consistent with the results reported by $\mathrm{Lu}$ et al. [11] that RSB could decrease the amount of extractable $\mathrm{Cd}$ in soil.

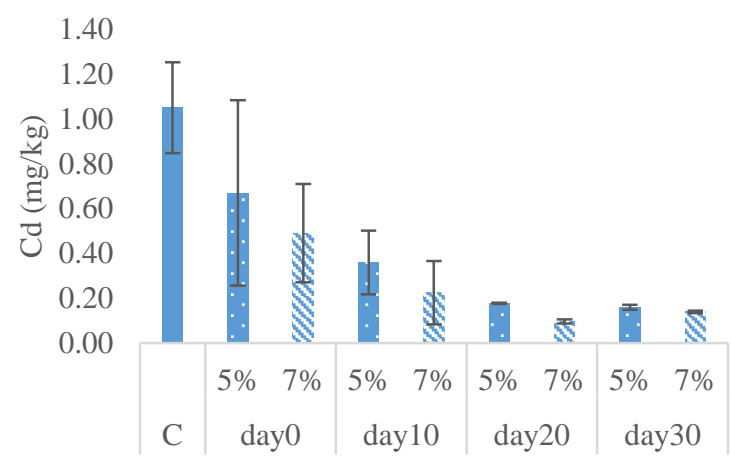

Fig. 10. Concentration of $\mathrm{CaCl}_{2}$-extracted $\mathrm{Cd}$ after incubation of 30 days.

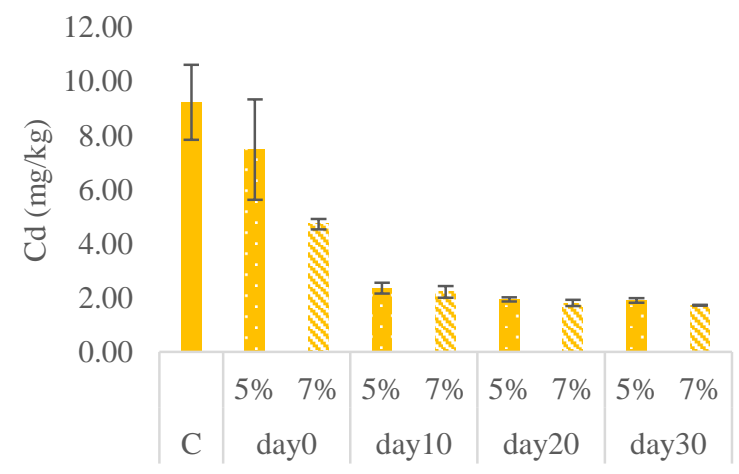

Fig. 11. Concentration of EDTA-extracted Cd after incubation of 30 days.
The concentration of $\mathrm{CaCl}_{2}$ and EDTA-extracted $\mathrm{Cd}$ in the soil decreased with longer curing time. This is a result of cadmium adsorption on the biochar surface. The increase in the amount of biochar in the contaminated soil resulted in greater adsorption of cadmium because of the increase of absorption sites on biochar surface. The results at day 20 showed less adsorption rate, indicating that adsorption sites were mostly occupied or saturated. As a result, the adsorption rate decreased. However, the reduction of $\mathrm{Cd}$ from the soluble form in saturated soil condition could also contribute to the decrease of extractable Cd as shown in Eh$\mathrm{pH}$ diagram of Cd suggested by Langmuir et al. [25].

According to the results, after incubation of 30 days, $\mathrm{RSB}$ at 5 and $7 \%$ was able to reduce the amount of $\mathrm{CaCl}_{2}$ extracted Cd by 84.84 and $90.85 \%$ and the amount of EDTA-extracted Cd by 79.44 and $81.26 \%$. However, when comparing the variance, there was no difference in the results of the experiments on day 20 and 30. This means that the incubation of $10-20$ days is adequate to achieve the maximum cadmium stabilization effect by RSB at the concentration used in this study.

\section{Conclusion}

Cadmium adsorption of paddy soil, BB, RHB, and RSB complied with Freundlich adsorption isotherm. The value of $\mathrm{K}_{\mathrm{F}}$ constant in the adsorption isotherm equation showed that the efficacy of each type of biochar for $\mathrm{Cd}$ adsorption could be ranked as $\mathrm{RSB}>\mathrm{BB}>\mathrm{RHB}>$ paddy soil. Cadmium stabilization efficacy was indicated by the quantity of $\mathrm{CaCl}_{2}$ and EDTA-extracted $\mathrm{Cd}$. It was found that the higher application rate and longer curing time resulted in lower amount of $\mathrm{CaCl}_{2}$ and EDTA-extracted $\mathrm{Cd}$. RSB at 5\% was the optimal application rate which could reduce $\mathrm{CaCl}_{2}$ and EDTA-extracted $\mathrm{Cd}$ by 83.15 and $79.00 \%$, respectively, with an optimal incubation period of 20 days.

\section{Acknowledgement}

This research was funded by the Agricultural Research Development Agency.

\section{References}

1. R.W. Simmons, P. Pongsakul, D. Saiyasitpanich and S. Klinphoklap, Elevated levels of cadmium and zinc in paddy soils and elevated levels of cadmium in rice grain downstream of a zinc mineralized area in Thailand: Implications for public health, Environmental Geochemistry and Health, 27 (2005): 501-511

2. Pollution Control Department, Survey and Assessment of Cadmium Distribution and Sources of Contamination in Mae Tao River Basin, Mae Sod District, Tak Province. (2007)

3. B. Prapakdee and J. Sangthong, An environmentally friendly approach to cadmium contaminated areas... From the test bottle to the real space, Environmental Journal, 20, 1 (2016): 1-13 
4. J. Jiang, et al., Immobilization of $\mathrm{Cu}(\mathrm{II}), \mathrm{Pb}(\mathrm{II})$ and $\mathrm{Cd}(\mathrm{II})$ by the addition of rice straw derived biochar to a simulated polluted Ultisol, Journal of Hazardous Materials, 229-230 (2012): 145-150

5. S. Khaokaew, and G. Landrot, A field-scale study of cadmium phytoremediation in a contaminated agricultural soil at Mae Sot District, Tak Province, Thailand: (1) Determination of Cdhyperaccumulating plants, Chemosphere, 138 (2015): 883-887

6. F. Jing, Biochar effects on soil chemical properties and mobilization of cadmium $(\mathrm{Cd})$ and lead $(\mathrm{Pb})$ in paddy soil, Soil Use and Management, 36, 2 (2020): 320-327

7. L. Cui, Continuous immobilization of cadmium and lead in biochar amended contaminated paddy soil: A five-year field experiment, Ecological Engineering, 93 (2016): 1-8

8. P. E. Dim and M. Termtanun, Treated Clay Mineral as Adsorbent for the Removal of Heavy Metals from Aqueous Solution, Applied Science and Engineering Progress, (2021)

9. A. Usman, Y. Kuzyakov and K. Stahr, Effect of Clay Minerals on Immobilization of Heavy Metals and Microbial Activity in a Sewage SludgeContaminated Soil (8 pp), The Journal of Soils and Sediments, 245-252 (2005)

10. F. Jing, Effects of wheat straw derived biochar on cadmium availability in a paddy soil and its accumulation in rice, Environmental Pollution, 257 (2020): 113592

11. K. Lu, X. Yang, G. Gielen, N. Bolan, Y.S. Ok, N.K. Niazi, S. Xu, G. Yuan, X. Chen, X. Zhang, D. Liu, Z. Song, X. Liu and $\mathrm{H}$. Wang, Effect of bamboo and rice straw biochars on the mobility and redistribution of heavy metals $(\mathrm{Cd}, \mathrm{Cu}, \mathrm{Pb}$ and $\mathrm{Zn})$ in contaminated soil, Journal of Environmental Management, 186 (2017): 285-292

12. A. Kowitwiwat and P. Sampanpanish, Comparison of physical and chemical properties of Bagasse, Napier grass and Acacia wood derived biochar on site contaminated, 18th National Environment Symposium. Environmental Engineering Society of Thailand, (1-10), (2019).

13. T. Abbas, M. Rizwan, S. Ali, M. Zia-ur-Rehman, M.F. Qayyum, F. Abbas, F. Hannan, J. Rinklebe, Y.S. Ok, Effect of biochar on cadmium bioavailability and uptake in wheat (Triticum aestivum L.) grown in a soil with aged contamination, Ecotoxicology and Environmental Safety, 140 (2017): 37-47

14. P. Maichu, P. Pinnoi and S. Jaroonwarasate, Comparison The Effects of Napier grass biochar and Bagasse biochar on absorption of cadmium contaminated soil, A Special Project Submitted in Partial Fulfillment of the Requirement for the Degree of Bachelor of Science (Environmental Chemistry),
Faculty of Science, King Mongkut's Institute of Technology Ladkrabang (2018)

15. D. Dong, Q. Feng, K. McGrouther, M. Yang, H. Wang and W. Wu, Effects of biochar amendment on rice growth and nitrogen retention in a waterlogged paddy field, The Journal of Soils and Sediments, 15 (2015): 153-162

16. G. Ma, H. Mao, Q. Bu, L. Han, A. Shabbir and F. Gao. Effect of Compound Biochar Substrate on the Root Growth of Cucumber Plug Seedlings, Agronomy, 10 (2020): 1-14

17. T.G. Ambaye, M. Vaccari, E.D. van Hullebusch, et al, Mechanisms and adsorption capacities of biochar for the removal of organic and inorganic pollutants from industrial wastewater, International Journal of Environmental Science and Technology, (2020)

18. A.W. Samsuri, F. Sadegh-Zadeh and B.J. SehBardan, Characterization of biochars produced from oil palm and rice husks and their adsorption capacities for heavy metals, International Journal of Environmental Science and Technology, (2013). doi: 10.1007/s13762-013-0291-3

19. J. Zhao, XJ. Shen, X. Domene, et al, Comparison of biochars derived from different types of feedstock and their potential for heavy metal removal in multiple-metal solutions, Scientific Reports, 9, 9869 (2019)

20. J. Komkiene and E. Baltrenaite, Biochar as adsorbent for removal of heavy metal ions [Cadmium(II), Copper(II), Lead(II), Zinc(II)] from aqueous phase, International Journal of Environmental Science and Technology, 13, (2016): 471-482

21. N. Puangpun, I. Suwimon and K. Piyamongkala, Adsorption Soluble Cutting Fluid Emulsion by Modified Chitosan with SLES, Applied Science and Engineering Progress, 12, 4 (2019): 243-252

22. D.L. Sparks, Environmental Soil Chemistry (Second Edition), (2003): 133-186

23. X. Cui, H. Hao, C. Zhang, Z. He and X. Yang, Capacity and mechanisms of ammonium and cadmium sorption on different wetland-plant derived biochars, Science of The Total Environment, 539 (2016): 566-575

24. J. Ma, W. Huang, X. Zhang, Y. Li, and N. Wang, The utilization of lobster shell to prepare low-cost biochar for high-efficient removal of copper and cadmium from aqueous: Sorption properties and mechanisms, Journal of Environmental Chemical Engineering, 9, 1 (2021): 104703

25. D. Langmuir, C. Paul, V. Bernard and C. Rufus, Issue Paper on the Environmental Chemistry of Metals, (2004). [Online]. Available from: https://www.researchgate.net/figure/Eh-pHdiagram-for-the-system-Cd-O-2-CO-2-S-H-2-O-forECd-10-7-mol-kg-ES-10-5_fig18_237330649

[Accessed 24 May 2021] 